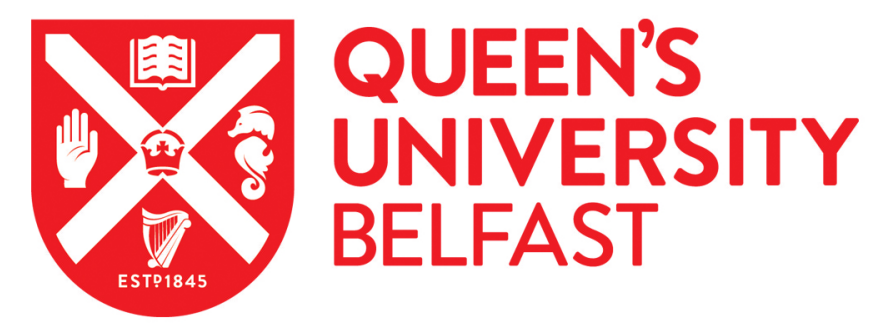

\title{
The cost-effectiveness of the SPHERE intervention for the secondary prevention of coronary heart disease
}

Gillespie, P., O'Shea, E., Murphy, A. W., Byrne, M. C., Byrne, M., Smith, S. M., Cupples, M., \& Study Team, S. P. H. E. R. E. (2010). The cost-effectiveness of the SPHERE intervention for the secondary prevention of coronary heart disease. International Journal of Technology Assessment in Health care, 26(3), 263-271. https://doi.org/10.1017/S0266462310000358

Published in:

International Journal of Technology Assessment in Health care

Queen's University Belfast - Research Portal:

Link to publication record in Queen's University Belfast Research Portal

\section{General rights}

Copyright for the publications made accessible via the Queen's University Belfast Research Portal is retained by the author(s) and / or other copyright owners and it is a condition of accessing these publications that users recognise and abide by the legal requirements associated with these rights.

Take down policy

The Research Portal is Queen's institutional repository that provides access to Queen's research output. Every effort has been made to ensure that content in the Research Portal does not infringe any person's rights, or applicable UK laws. If you discover content in the Research Portal that you believe breaches copyright or violates any law, please contact openaccess@qub.ac.uk. 


\title{
ASSESSMENTS
}

\section{The cost-effectiveness of the SPHERE intervention for the secondary prevention of coronary heart disease}

\author{
Paddy Gillespie, Eamon O'Shea, Andrew W. Murphy, Mary C. Byrne, \\ Molly Byrne \\ National University of Ireland, Galway
}

Susan M. Smith
Trinity College Dublin

Margaret E. Cupples

Queen's University Belfast

for the SPHERE Study Team

Objectives: The Secondary Prevention of Heart disEase in geneRal practicE (SPHERE) trial has recently reported. This study examines the cost-effectiveness of the SPHERE intervention in both healthcare systems on the island of Ireland.

Methods: Incremental cost-effectiveness analysis. A probabilistic model was developed to combine within-trial and beyond-trial impacts of treatment to estimate the lifetime costs and benefits of two secondary prevention strategies: Intervention - tailored practice and patient care plans; and Control - standardized usual care.

Results: The intervention strategy resulted in mean cost savings per patient of $€ 512.77$ (95 percent confidence interval [Cl], -1086.46-91.98) and an increase in mean quality-adjusted life-years (QALYs) per patient of 0.0051 (95 percent $\mathrm{Cl}$, $-0.0101-0.0200)$, when compared with the control strategy. The probability of the intervention being cost-effective was 94 percent if decision makers are willing to pay $€ 45,000$ per additional QALY.

\footnotetext{
Andrew W. Murphy, Margaret E. Cupples, and Susan M. Smith conceived the study and together with Molly Byrne and Mary C. Byrne participated in the design of the trial and intervention. Paddy Gillespie and Eamon O'Shea undertook the acquisition and analysis of the health economic data. All authors participated in critical revision of the manuscript, and have seen and approved the final version. This study was funded by the Health Research Board and Irish Heart Foundation. The funders had no part in the design of the study; the collection, analysis, and interpretation of the data; the writing of the report; and the decision to submit the article for publication. We thank the other members of the SPHERE study team, including C. Leathem, A. Houlihan, M O'Malley, V. Spillane, H. Grealish, and P. Ryan (research nurses); M. Corrigan, M. D'Eath, and J. Wilson (qualitative researchers); and A. Kelly, J. Newell, and M. Donnelly (statistical and policy advisers). We also thank the patients and practitioners who participated in the study.
} 
Conclusions: Decision makers in both settings must determine whether the level of evidence presented is sufficient to justify the adoption of the SPHERE intervention in clinical practice.

\section{Keywords: Coronary heart disease, Secondary prevention, General practice, Cost-effectiveness analysis}

Coronary heart disease (CHD) is a leading cause of death and illness in Ireland. Secondary prevention, involving the long-term management of cardiovascular risk factors among people who have been diagnosed with established disease, has been recommended as a key strategy for reducing levels of CHD (9). Moreover, as the majority of symptomatic individuals regularly attend their general practitioner (GP), primary care has been identified as an ideal setting for secondary prevention initiatives in many countries including the Republic of Ireland and Northern Ireland. A recent systematic review of disease management programs targeting patients with CHD confirmed that such programs are effective (6). Reviewers concluded, however, that several important issues require further clarification, including the optimal mix of interventions and their cost-effectiveness (6).

The Secondary Prevention of Heart disEase in geneRal practicE (SPHERE) study addressed these issues directly. Full details of the trial methods are published elsewhere (18). In brief, a cluster randomized controlled trial (RCT) recruited forty-eight practices and 903 patients with CHD (documented myocardial infarction [MI], coronary artery bypass grafting, angioplasty, or angina) in both healthcare systems on the island of Ireland. Practices were randomized to the intervention group, where practices and patients had access to tailored care plans (Practices received training in prescribing and behavior change, administrative support, quarterly newsletter; Patients received motivational interviewing, goal identification and target setting for lifestyle change, fourmonthly review visits), or to the control group, where patients received existing primary care, consisting of unstructured and irregular patient follow-up (18). Details on the baseline characteristics of the patient populations in each group are presented in Supplementary Table 1, which can be viewed online at www.journals.cambridge.org/thc2010018. Forty-two patients in the intervention group and 23 patients in the control group were lost to follow-up, leaving 838 (92.8 percent) patients in the trial based analysis. Over a mean follow-up of 18 months, the trial showed a significant reduction in the numbers admitted to hospital for the intervention group compared with the control group (95 percent CI, 1.53-2.60; $p=0.03$ ) (18). There were no differences between groups in the other primary outcomes: blood pressure, total cholesterol, physical and mental health status, as measured by the SF-12 (18).

In addition to clinical effectiveness, any decision regarding the adoption of a healthcare program in a resource constrained healthcare system will depend upon its expected cost-effectiveness; that is, on whether it generates improvements in patients' health at an acceptable cost. This study reports the results of the economic evaluation of the SPHERE study. We construct a decision analytic model, based on published epidemiological risk equations, which combines within-trial results with long-term projections to capture the impacts of treatment over the remainder of the patient's lifetime. In the context of chronic disease, the appropriate time horizon of analysis is the patient's lifetime, as healthcare programs will have long-term implications for both costs and outcomes (11).

\section{METHODS}

\section{Overview}

The cost-effectiveness analysis incorporates a trial-based component and a model-based component. Evidence collected (by means of questionnaires, chart searches, and consultation records) on resource use and clinical outcome measures, combined with external valuation data in the form of unit costs and utilities, provided the basis for the analysis within the trial follow-up period. The statistical analysis was conducted on an intention to treat basis, and in accordance with current guidelines for cluster RCTs (3). The model composed of a probabilistic Markov model, which combines data collected alongside the trial with additional evidence from Irish and international sources to extend the time horizon of the evaluation. The perspective of the healthcare provider was adopted and health outcomes were assessed in terms of quality-adjusted life-years (QALYs). The time horizon of the analysis was the patient's lifetime and future costs and benefits were discounted at an annual rate of 3.5 percent (20).

\section{Decision Analytic Model}

The modeling structure was developed to reflect the natural history of the disease (Supplementary Figure 1, which can be viewed online at www.journals.cambridge.org/thc2010018). Disease progression is modeled using a Markov process with three discrete health states: "CHD," "Post-MI," and "Dead." A series of published risk equations form the basis for the transition probabilities in the model. Annual risk of non-CHD mortality is modeled using age- and sex-specific Irish life tables (5). Annual risk of recurrent CHD is modeled using Framingham risk equations by D'Agostino et al. (8), 
Table 1. Categories of Resource Use and Unit Costs

\begin{tabular}{|c|c|c|c|c|}
\hline Within-trial analysis & $\begin{array}{l}\text { North Ire } \\
(€)\end{array}$ & Source & $\begin{array}{l}\text { Rep of Ire } \\
(€)\end{array}$ & Source \\
\hline Intervention setup & 213 & Study accounts & 213 & Study accounts \\
\hline \multicolumn{5}{|l|}{ Healthcare resources } \\
\hline GP visit & 46 & Netten \& Curtis (2006) & 45 & ORC \\
\hline Practice nurse visit & 11 & Netten \& Curtis (2006) & 7 & INO \\
\hline Inpatient day & 709 & Reference Costs, DHSSPS & 659 & Casemix Unit, DOHC \\
\hline Outpatient visit & 186 & Reference Costs DHSSPS & 171 & Casemix Unit, DOHC \\
\hline A\&E visit & 154 & Reference Costs DHSSPS & 210 & Casemix Unit, DOHC \\
\hline Drugs & $\mathrm{n} / \mathrm{a}$ & MIMS, Ireland & $\mathrm{n} / \mathrm{a}$ & MIMS, Ireland \\
\hline \multicolumn{5}{|l|}{ Patient resources } \\
\hline Car per mile & 0.59 & IRO & 0.98 & DOF \\
\hline Bus per mile & 1.91 & Translink/Metro, Belfast & 1.50 & Dublin/Galway Bus \\
\hline Taxi (min fare) & 3.96 & DOE & 3.40 & www.taxi.ie \\
\hline Taxi (per additional mile) & 1.76 & DOE & 1.43 & www.taxi.ie \\
\hline \multicolumn{5}{|l|}{ Time input } \\
\hline Hourly rate - employed & 19 & Leal et al. (2006) & 17 & Leal et al. (2006) \\
\hline Hourly rate - other & 7 & Leal et al. (2006) & 7 & Leal et al. (2006) \\
\hline Beyond-trial analysis & $€$ & Source & & \\
\hline \multicolumn{5}{|l|}{ Healthcare resources } \\
\hline CHD & 1607 & SPHERE baseline data & & \\
\hline Stable angina & 3486 & Casemix Unit, DOHC & & \\
\hline Unstable angina & 3921 & Casemix Unit, DOHC & & \\
\hline Myocardial infarction & 4821 & Casemix Unit, DOHC & & \\
\hline Post MI & 1607 & SPHERE Baseline Data & & \\
\hline
\end{tabular}

Source references:

Netten A, Curtis J. (2006) Unit costs of health and social care. Canterbury: Personal Social Services Research Unit, University of Kent; ORC: Office of Revenue Commissioner, Dublin; INO: Irish Nurses Organisation, Dublin; DHSSPS: Department of Health, Social Services and Public Safety; DOHC: Department of Health and Children; MIMS: Monthly Index of Medical Specialities, Ireland; IRO: Inland Revenue Office, Belfast; DOF: Department of Finance, Dublin; DOE: Department of the Environment, Belfast; Leal et al. Economic burden of cardiovascular diseases in the enlarged European Union. European Heart Journal 2006;13:1610-1619.

Note. All prices reported in 2006 Euros $(€)$.

North Ire, Northern Ireland; Rep of Ire, Republic of Ireland; CHD, coronary heart disease; MI, myocardial infarction; GP, general practitioner; A\&E, accident and emergency department.

which estimate the relationship between current cardiovascular risk factor profile and the probability of experiencing subsequent coronary events. Although contentious (15), the choice of Framingham risk equations was determined by the absence of an equivalent risk model for a secondary prevention population in a European setting.

The model allows for a user-specified time horizon of up to 50 years, by which time all individuals are predicted to reside in the "Dead" state. The risk equations are based on a mean follow-up of 4 years, but the statistical relationships they represent are assumed to apply over the entire time horizon of the analysis. An important assumption of the model relates to the duration of the treatment effect adopted. It is not appropriate to assume that the effect of treatment, in terms of a patient's cardiovascular risk factor profile observed at the end of the trial, would sustain for the remainder of the patient's lifetime. In the base-case analysis, data collected at trial follow-up were entered into the risk equations to estimate CHD risk for the subsequent 4 years, that is, the mean follow-up of the risk equations by D'Agostino et al. (8). Beyond 4 years and for the remainder of the analysis, cardiovascular risk factor profiles for the alternative treatment groups are assumed to be the same.

Separate risk equations were constructed for men and women using data from the original Framingham Study cohort and the Offspring-Spouse Study (8). For men, the equation includes age, diabetes, and the ratio of Total Cholesterolto-HDL Cholesterol. For women, systolic blood pressure and smoking status are also included. Overall predicted risk is allocated into one of four CHD events (MI, unstable angina [UA], stable angina [SA], or CHD death) using data from an Irish observational study of patients with existing CHD (10). The relative increase in mortality risk for the first versus subsequent years post-MI was adopted from a published report examining alternative treatment options for acute coronary syndrome (23). 
The model is run for the two patient cohorts: intervention and control. For each group, the relevant input parameter data were estimated from the trial and entered into the risk equations. As total cholesterol and systolic blood pressure were primary outcomes in the clinical study, their inclusion incorporates the relative effectiveness of the treatment alternatives in the beyond-trial analysis. These parameters were estimated using a generalized estimating equations (GEE) multivariate regression model, controlling for treatment arm, baseline values, and a range of clinically specified covariates and factors (13). The input parameters of interest were obtained from the linear predictions from the regression analysis, using the method of recycled predictions (12). In addition, sex-specific estimates for age, smoking status, diabetes status, and HDL cholesterol were estimated from pooled data for both intervention and control patients at baseline. This approach is adopted to ensure that the effectiveness of the alternative treatments is incorporated through the impacts on the primary clinical outcomes only.

The model is probabilistic in that specified input parameters are entered as probability distributions to reflect second order uncertainty and Monte Carlo simulation is used to translate the precision in each variable into a measure of uncertainty in overall cost-effectiveness. This process was repeated 1,000 times, with each simulation involving a random draw from each of the assigned input parameter distributions, thereby generating 1,000 sets of results for the costs and benefits of the intervention and control strategies. The simulated results were used to estimate the expected costs and benefits of treatment, the difference across treatment groups, and the associated uncertainty.

\section{Costs}

Three elements of costs were included in the analysis, all of which were expressed in 2006 Euros $(€)$. The first related to the healthcare resources expended over the course of the trial. Costs associated with intervention set-up were detailed in the study accounts and included: training sessions, educational materials and consumables, post, packaging and telephone calls, research nurse support, the baseline consultation, and travel costs associated with these activities. In addition, the costs associated with the use of primary care services, specifically GP and practice nurse consultations, prescriptions, and secondary care services, including hospital admissions, outpatient consultations, and accident and emergency visits, were estimated.

The costs to patients, in terms of time input and travel expenses over the course of the trial, were estimated. Whereas these costs were estimated for each treatment arm and are presented in the study, they are not included in the overall cost-effectiveness analysis so to ensure comparability with other studies.

The third element of costs related to the healthcare resources consumed beyond the end of the trial. First, an annual cost per patient was estimated to capture the health- care burden associated with treating patients with CHD in the community. Second, the hospitalization cost per predicted nonfatal coronary event, that is, SA, UA, and MI, was included.

Unit cost data for the relevant resource use items were collected for both Northern Ireland and the Republic (Table 1), and were assigned on the basis of the patient's country of origin. Where necessary, unit costs were up-rated to 2006 prices using the hospital and community health services pay and price inflation index (19) for Northern Ireland, and the health component of the consumer price index (5) for the Republic. Pounds were converted to Euros using the 2006 exchange rate from the Central Bank of Ireland (4).

\section{QALYs}

The health outcomes of treatment were expressed in terms of QALYs. Health-related quality of life was assessed within the trial using the SF-12 questionnaire (25). Responses were transformed to utility weights using the SF-6D preference based algorithm (2). Trial based QALYs were estimated using the area-under-the-curve method from SF-6D scores at baseline and follow-up, controlling for differences in baseline scores between treatment groups (17).

Impacts on health-related quality of life beyond the end of the trial were estimated by adjusting projected life expectancy using appropriate utility weights. As intervention and control patients were deemed equivalent at trial entry, the combined baseline SF-6D scores for all patients were used to estimate the utility weight for a patient with CHD in the Irish setting. The reduction in health-related quality of life resulting from experiencing non fatal coronary events, specifically UA and MI, was adopted from Lacey and Walters (16), who provide estimates of utility for the first and subsequent years following MI.

\section{Analysis}

Cost-effectiveness is assessed by relating the mean differential cost per patient between the two strategies, to their differential effectiveness. To explore the uncertainty surrounding the point estimates for cost-effectiveness, a probabilistic sensitivity analysis was undertaken. These results are presented using cost-effectiveness acceptability curves (CEACs), which estimate the probability that a treatment option is cost-effective dependent on how much the healthcare system is willing to pay for additional health gain (11).

As the trial recruited practices from two different healthcare systems, a subgroup analysis was undertaken to explore the cost-effectiveness results for each jurisdiction. In brief, the Republic of Ireland has a mixed healthcare system, with free access to primary care services for those judged less able to pay and those aged 70 years and over (32 percent of population registered in 2005) (18). Northern Ireland is served by the National Health Service, with no charges for access to primary or hospital care. For each run, the required 
input parameters were estimated for the alternative treatment groups within each system.

In addition, several assumptions of the modeling approach were assessed using one-way sensitivity analyses. First, as alternative Framingham equations for a primary prevention population have been shown to overestimate coronary risk in European settings (15), the level of "accuracy" is varied to 10 percent, 25 percent, 50 percent, and 75 percent to reflect different levels of over-estimation. Second, duration of treatment effect is varied to 1 year and for the remainder of the patient's lifetime. Third, the discount rates were varied to 0 percent and 10 percent.

\section{RESULTS}

The results from the analysis are presented in the following section. The input parameter data adopted for the analysis are presented in Supplementary Table 2, which can be viewed online at www.journals.cambridge.org/thc2010018.

\section{Costs}

The key elements of resource use over the course of the trial, and the resultant healthcare and patient costs are summarized in Table 2. The total cost of implementing the intervention was $€ 94,447$, giving a mean cost per patient of $€ 213$. The difference in mean healthcare and patient costs across treatment groups at trial follow-up was estimated, adjusting for variations in the costs that occurred in the 12 months before baseline. To account for the skewed and hierarchical nature of the cost data, a GEE regression model, with an identity link function, an exchangeable correlation structure, and a Gamma variance function was adopted for the analysis. The results indicate that the intervention was associated with reductions of $€ 509.31$ (95 percent CIs, -1158.34-139.72) and $€ 43$ (95 percent CIs, -101.54-15.64) in healthcare and patient costs, respectively.

The overall lifetime healthcare costs, composed of within-trial estimates and long-term projections, are presented in Table 3. These indicate that the intervention was associated with a mean cost saving of $€ 512.77$ (95 percent CIs, -1086.46-91.98) compared with control. Neither the results from the within-trial nor the lifetime analyses were statistically significant at the 5 percent level.

\section{QALYs}

The key elements in the estimation of QALYs over the course of the trial are detailed in Table 2. The difference in mean QALYs per patient between groups at trial follow-up was estimated, adjusting for differences in SF-6D scores at baseline. In this case, a GEE regression model, assuming a Gaussian variance function was adopted for the statistical analysis and indicates that the intervention was associated with a 0.003 (95 percent CIs, -0.012-0.007) reduction in mean QALYs per patient compared with control.
The model combined within-trial estimates with longterm quality adjusted life expectancy projections to estimate the overall lifetime benefits of treatment. The results from the incremental analysis indicate that intervention was associated with an average increase of 0.0051 (95 percent CIs, -0.01010.0200) per patient compared with control. This suggests that the projected quality-adjusted life expectancy associated with the intervention offset the incremental losses that were observed over the course of the trial. Nonetheless, neither the results from the within-trial nor lifetime analyses were statistically significant at the 5 percent level.

\section{Cost-Effectiveness}

Overall, on the basis of expected cost-effectiveness, the intervention dominates control: that is, it generates higher mean QALYs and results in lower health service costs. The uncertainty in the analysis is presented graphically in Supplementary Figures 2 and 3, which can be viewed online at www.journals.cambridge.org/thc2010018. The probability of the intervention being, on average, less costly is 96 percent. In Ireland, a cost-effectiveness threshold value in the region of $€ 45,000$ per QALY has been proposed for health technology appraisal (1). At this threshold, there is a probability of 94 percent that the intervention is cost-effective.

There is evidence that the results for the incremental cost and incremental effectiveness analyses were somewhat different across the two settings (Supplementary Tables 3, 4, and 5, which can be viewed online at www.journals.cambridge.org/thc2010018). In the Republic, the reduction in mean cost per patient associated with the intervention was greater than that in the North. Conversely, the improvement in mean QALYs per patient associated with the intervention was superior in the North than in the Republic. Nonetheless, it is the combination of these variables which determines overall cost-effectiveness, and at a threshold value of $€ 45,000$ per additional QALY, the probability of the intervention being cost-effective is 93 percent in the Republic and 90 percent in the North.

The results of the sensitivity analyses reveal that altering the assumptions of the base-case model did not impact, to a great degree, the likelihood of the intervention being costeffective (Supplementary Table 5).

\section{DISCUSSION}

A decision model was constructed to undertake the costeffectiveness analysis of the SPHERE intervention for the secondary prevention of CHD in both health systems on the island of Ireland. The analysis was based largely on data collected alongside the clinical trial, augmented with evidence from Irish, UK, and U.S. published sources. The intervention was associated with an overall mean lifetime healthcare cost saving per patient of $€ 512.77$ and generated a mean improvement in lifetime health outcomes of 0.0051 QALYs per patient. The true cost savings are likely to be greater than 
Table 2. Within-Trial Results

\begin{tabular}{|c|c|c|c|c|}
\hline \multirow{2}{*}{$\begin{array}{l}\text { Variable } \\
\text { Resource item }\end{array}$} & \multicolumn{2}{|c|}{$\begin{array}{c}\text { Intervention } N=444 \\
\text { Mean }(\mathrm{SD})\end{array}$} & \multicolumn{2}{|c|}{$\begin{array}{c}\text { Control } N=459 \\
\text { Mean }(\mathrm{SD})\end{array}$} \\
\hline & Resource use & Cost $(€)$ & Resource use & Cost $(€)$ \\
\hline \multicolumn{5}{|l|}{ Healthcare resources } \\
\hline GP visits & $8.3(5.7)$ & $373.60(257.39)$ & $7.5(5.9)$ & $344.24(269.39)$ \\
\hline Practice nurse visits & $4.6(4.2)$ & $39.60(37.53)$ & $1.8(2.2)$ & $15.83(20.21)$ \\
\hline Inpatient days & $2.0(6.2)$ & $1299.02(4032.24)$ & $3.0(7.4)$ & $1944.57(4748.88)$ \\
\hline Outpatient visits & $2.7(3.6)$ & $526.93(683.29)$ & $3.6(4.1)$ & $696.82(804.27)$ \\
\hline A\&E visits & $0.3(0.6)$ & $52.09(111.28)$ & $0.5(0.9)$ & $85.17(166.89)$ \\
\hline Antiplatelet agents & $\mathrm{n} / \mathrm{a}$ & $0.43(0.71)$ & $\mathrm{n} / \mathrm{a}$ & $0.48(0.75)$ \\
\hline Lipid Lowering agents & $\mathrm{n} / \mathrm{a}$ & $1.33(0.79)$ & $\mathrm{n} / \mathrm{a}$ & $1.36(0.81)$ \\
\hline Antihypertensive agents & $\mathrm{n} / \mathrm{a}$ & $0.83(0.59)$ & $\mathrm{n} / \mathrm{a}$ & $0.82(0.70)$ \\
\hline Total drugs & $\mathrm{n} / \mathrm{a}$ & $2.61(1.33)$ & $\mathrm{n} / \mathrm{a}$ & $2.64(1.45)$ \\
\hline Intervention setup & $\mathrm{n} / \mathrm{a}$ & $213(\mathrm{n} / \mathrm{a})$ & $\mathrm{n} / \mathrm{a}$ & $0(\mathrm{n} / \mathrm{a})$ \\
\hline TOTAL HEALHCARE COST & $\mathrm{n} / \mathrm{a}$ & $3939.71(4334.36)$ & $\mathrm{n} / \mathrm{a}$ & $4539.68(5210.17)$ \\
\hline \multicolumn{5}{|l|}{ Patient resources } \\
\hline Travel expenses & $\mathrm{n} / \mathrm{a}$ & $115.51(181.30)$ & $\mathrm{n} / \mathrm{a}$ & $147.48(222.13)$ \\
\hline Time input & $\mathrm{n} / \mathrm{a}$ & $139.39(134.61)$ & $\mathrm{n} / \mathrm{a}$ & $142.64(139.74)$ \\
\hline TOTAL PATIENT COST & $\mathrm{n} / \mathrm{a}$ & $254.90(264.73)$ & $\mathrm{n} / \mathrm{a}$ & $290.12(321.50)$ \\
\hline Health outcome & \multicolumn{2}{|c|}{$\begin{array}{l}\text { Intervention } \\
\text { Mean (SD) }\end{array}$} & \multicolumn{2}{|c|}{$\begin{array}{c}\text { Control } \\
\text { Mean (SD) }\end{array}$} \\
\hline Baseline SF6D score & \multicolumn{2}{|c|}{$0.6889(0.0730)$} & \multicolumn{2}{|c|}{$0.6866(0.0817)$} \\
\hline Follow up SF6D score & \multicolumn{2}{|c|}{$0.6887(0.0808)$} & \multicolumn{2}{|c|}{$0.6912(0.0765)$} \\
\hline$Q A L Y s$ & \multicolumn{2}{|c|}{$1.0324(0.0933)$} & \multicolumn{2}{|c|}{$1.0309(0.0894)$} \\
\hline
\end{tabular}

Note. Completeness of data at follow up: Cost Data: Intervention patients: $98 \%$ completeness for data on primary care visits, $96 \%$ for days in hospital, $98 \%$ for outpatient, $98 \%$ for A\&E visits, and $82 \%$ for cardiovascular prescriptions. Control patients: $98 \%$, 97\%, 98\%, 98\% and 88\%, respectively. QALY Data: Intervention patients: There was $85 \%$ completeness for data on baseline SF6D score, 76\% for follow up SF6D score, and 65\% for QALYs. Control patients: 88\%, 73\%, and 65\%, respectively.

GP, general practitioner; A\&E, accident and emergency department; QALYS, quality-adjusted life-years.

reported as we excluded costs to patients (i.e., time and travel) from the final analysis.

These findings reflect those from the clinical study, which reported that the intervention led to a reduction in the number of patients admitted to hospital, but did not generate additional clinical benefits in terms of blood pressure, cholesterol, or health-related quality of life. Our results indicate that cost savings from the reduction in admissions offset the implementation and additional primary care costs of the intervention, leading to an overall reduction in healthcare costs relative to control. However, there were no statistically significant differences between groups in final cost or effect end point. In such circumstances, and where equivalence has not been demonstrated, incremental cost-effectiveness ratios should be calculated and the uncertainty surrounding such ratios quantified (14). We estimated the uncertainty in cost per QALY figures using CEACs, which indicate that the probability of the intervention being cost-effective remains appreciably higher than 80 percent across a wide range of threshold values, and across both healthcare systems. It will ultimately be the remit of decision makers in both jurisdictions to determine whether such a level of certainty is sufficient to justify the adoption of the intervention in clinical practice. Moreover, they should be clear that it is the differ- ence in costs that is the main driver in the cost-effectiveness results.

Of interest was the difference in the nature of the impact of the intervention in the two healthcare systems included in the study. This is not unexpected given their differing approaches with respect to the funding and provision of healthcare services in general and secondary prevention services in particular. This was reflected in the observed differences in the service utilization across settings, which directly influence the cost of the intervention and control strategies in each system. Moreover, we previously reported differences in baseline characteristics between participants recruited in the North and the Republic-overall those in North had better levels of control of their cardiovascular risk factors but those in the Republic reported better self-assessed quality of life (7). The latter may be linked to the greater improvement in mean QALYs per patient associated with the intervention in the North than in the Republic. These issues notwithstanding, the intervention was associated with reduced costs and improved health in both systems and policy makers must decide whether the uncertainty at their chosen threshold value is acceptable. An important issue underlying this analysis is that of the true threshold value in each jurisdiction. It is likely to be the case that each country has a distinct threshold value 
Table 3. Incremental Cost-Effectiveness Results

\begin{tabular}{|c|c|c|}
\hline Cost analysis & \multicolumn{2}{|c|}{$\begin{array}{c}\text { Incremental analysis } \\
\text { (Intervention minus control) }\end{array}$} \\
\hline Difference in within-trial healthcare cost (95\% CIs) & \multicolumn{2}{|c|}{$\begin{array}{c}-509.31 \\
(-1158.34,139.72)\end{array}$} \\
\hline Difference in within-trial patient cost (95\% CIs) & \multicolumn{2}{|c|}{$\begin{array}{c}-42.95 \\
(-101.54,15.64)\end{array}$} \\
\hline \multirow[t]{2}{*}{ Lifetime healthcare cost (95\% CIs) } & Intervention & Control \\
\hline & $\begin{array}{c}21,361.53 \\
(11,110.23,39,322.38)\end{array}$ & $\begin{array}{c}21,874.30 \\
(11,609.31,40,014.34)\end{array}$ \\
\hline Difference in lifetime healthcare cost (95\% CIs) & \multicolumn{2}{|c|}{$\begin{array}{c}-512.77 \\
(-1086.46,91.98)\end{array}$} \\
\hline Effectiveness analysis & \multicolumn{2}{|c|}{$\begin{array}{c}\text { Incremental analysis } \\
\text { (Intervention minus control) }\end{array}$} \\
\hline Difference in within-trial QALYs (95\% CI) & \multicolumn{2}{|c|}{$\begin{array}{c}-0.003 \\
(-0.012,0.007)\end{array}$} \\
\hline \multirow[t]{2}{*}{ Lifetime QALYs (95\% CIs) } & Intervention & Control \\
\hline & $\begin{array}{c}7.8986 \\
(7.70,8.08)\end{array}$ & $\begin{array}{c}7.8935 \\
(7.69,8.08)\end{array}$ \\
\hline Difference in lifetime QALYs $(95 \% \mathrm{CI})$ & \multicolumn{2}{|c|}{$\begin{array}{c}0.0051 \\
(-0.0101,0.0200)\end{array}$} \\
\hline
\end{tabular}

Note. Within-Trial Cost Analyses: GEE regression model, with an identity link function, a Gamma variance function, and exchangeable correlation structure. All models estimated controlling for baseline cost in the 12 months prior to trial. Within-Trial QALY Analysis: GEE regression, with an identity link function, a Gaussian variance function, and exchangeable correlation structure. Model estimated controlling for baseline SF6D scores. Beyond-Trial Analyses: Expected values estimated from 1,000 simulations from the probabilistic model. All 95\% confidence intervals estimated using the percentile method.

CI, confidence interval; GEE, generalized estimating equations; QALYs, quality-adjusted life-years.

which reflects its own healthcare budget constraints. Our results reveal that at lower threshold values the intervention is more likely to be more cost-effective in the Republic than in the North. This may be relevant given the current economic climate and its potential impact on healthcare budgets and the knock on effects in terms of an acceptable threshold value for additional health gain.

There are several limitations in the analysis. In general, the issue of transferability of data from external sources to the Irish setting is an important consideration throughout. This is particularly true in the case of the adopted risk equations which were estimated for an American population with CHD. Furthermore, as neither the standard errors of the coefficients or the covariance across the covariates were available for the equations, it was not possible to fully incorporate the uncertainty surrounding the equations in the probabilistic sensitivity analysis. In the adopted approach, trial-based healthcare costs and QALYs are inputted in the model as standalone parameters, the assumption being that they act independently. This is unlikely to be the case as the health outcome that an individual experiences will be related, to some degree or another, to the healthcare services they use: the actual result for the correlation between healthcare costs and QALYs was -0.03. Consideration was given to adapt- ing the model to address this issue; however, we decided to proceed with the assumption of independence given that the observed correlation was not significant. An important assumption of the modeling approach relates to how long the effect of treatment persists following the end of the trial. While the approach adopted may be viewed as somewhat arbitrary, we believe it to be appropriate given the evidence that the benefits of secondary prevention programs extend beyond the length of a trial (6).

The results from our study are similar to previous studies which compared disease management programs for the secondary prevention of CHD with "usual care" in the United Kingdom (21;22;24). These studies were trial based evaluations, with a time horizon of 1 year (24), 2 years (21), and 5 years (22), respectively. O'Neill et al. (21) reported significant improvements in survival and self-assessed quality of life with no significant difference in healthcare costs associated with the intervention. Raftery et al. (22) reported a 70 percent probability that their intervention strategy was cost-effective at a threshold value $£ 5,000$ per QALY. Similarly, Turner et al. (24) reported a 90 percent probability that their intervention strategy was cost-effective at of threshold value $£ 30,000$ per QALY. A fourth study by Johnston et al. (14) compared three alternative strategies for promoting 
secondary prevention in primary care over the patients' lifetime by means of a cluster RCT and a decision model. They report that two strategies for promoting secondary prevention, "Recall to GP" and "Recall to Nurse," were not likely to be cost-effective when compared with the control strategy of "Audit and Feedback." They do suggest, however, that a control strategy of "usual care" may have produced more favorable findings (14). The results from our study add further weight to the assertion that such programs may be a cost-effective alternative to "usual care." In addition, we show that the cost-effectiveness of such programs of care is broadly similar across different healthcare systems.

\section{POLICY IMPLICATIONS}

Our results suggest that the SPHERE intervention is likely to be cost-effective in both healthcare systems on the island of Ireland. The cost-effectiveness results are predominantly determined by differences in costs between treatment arms, particularly in relation to hospital admissions. Decision makers in both settings must determine whether the level of evidence presented, including the estimated uncertainty, is sufficient to justify the adoption the intervention in clinical practice.

\section{SUPPLEMENTARY MATERIAL}

Supplementary Table 1

Supplementary Table 2

Supplementary Table 3

Supplementary Table 4

Supplementary Table 5

Supplementary Figure 1

Supplementary Figure 2

Supplementary Figure 3

www.journals.cambridge.org/thc 2010018

\section{CONTACT INFORMATION}

Paddy Gillespie, MSc, PhD (paddy.gillespie@nuigalway. ie), Post Doctoral Researcher in Economics, Eamon O'Shea, MA, MSc, PhD (eamon.oshea@nuigalway.ie), Professor of Economics, Andrew W. Murphy, MB, MD, FRCGP, MICGP (andrew.murphy@ nuigalway.ie), Professor of General Practice, Mary C. Byrne, MSc, PhD (mary.byrne@nuigalway.ie), Lecturer in General Practice, Molly Byrne, MSc, PhD (molly.byrne@nuigalway.ie), Lecturer in Psychology, National University of Ireland, Galway, University Road, Galway, Ireland

Susan M. Smith, MD, MCh, BAO, MRCPI, MRCGP (susmith@tcd.ie), Senior Lecturer, Primary Care, Trinity College Dublin, Trinity College Centre for Health Science, AM$\mathrm{NCH}$, Tallaght, Dublin 24, Ireland

Margaret E. Cupples, BSc (Hons), MD, FRCGP (m. cupples@qub.ac.uk), Clinical Reader, UKCRN Centre of Ex- cellence for Public Health Research (NI), Queen's University Belfast, QUB Department of General Practice, Dunluce Health Centre, 1 Dunluce Avenue, Belfast BT9 7HR, North Ireland,

\section{CONFLICT OF INTEREST}

All authors report their institutions have received funding for the study from the Health Research Board in Ireland.

\section{REFERENCES}

1. Barry M, Tilson L. Recent developments in pricing and reimbursement of medicines in Ireland. Expert Rev Pharmacoecon Outcomes Res. 2007;7:605-611.

2. Brazier JE, Roberts J. Estimating a preference-based index from the SF-12. Med Care. 2004;42:851-859.

3. Campbell MK, Elbourne DR, Altman DG, et al. CONSORT statement: Extension to cluster randomised trials. $B M J$. 2004;328:702-708.

4. Central Bank of Ireland. Dublin (www.centralbank.ie). (Accessed June 2008)

5. Central Statistics Office. Dublin (www.cso.ie). (Accessed June 2008)

6. Clark AM, Hartling L, Vandermeer B, McAlister FA. Metaanalysis: Secondary prevention programs for patients with coronary artery disease. Ann Intern Med. 2005;143:659-672.

7. Cupples ME, Byrne MC, Smith SM, Leathem C, Murphy AW. Secondary prevention of cardiovascular disease in different primary healthcare systems, with and without pay-forperformance. Heart. 2008;94:1594-1600.

8. D'Agostino RB, Russell M, Huse DM, et al. Primary and subsequent coronary risk appraisal: New results from The Framingham Study. Am Heart J. 2000;139:272-281.

9. De Backer G, Ambrosioni E, Borch-Johnsen K, et al. European guidelines on cardiovascular disease prevention in clinical practice. Eur Heart J. 2003;24:1601-1610.

10. Department of Health and Children. The National Heartwatch Programme: Clinical report - March 2003 to December 2005. Dublin; 2006.

11. Drummond MF, Sculpher MJ, Torrance GW, O'Brien J, Stoddart GL. Methods for the economic evaluation of health care programmes. New York: Oxford University Press;2005.

12. Glick HA, Doshi JA, Sonnad SS, Polsky D. Economic evaluation in clinical trials. New York: Oxford University Press; 2007.

13. Hardin JW, Hilbe JM. Generalised estimating equations. London: Chapman and Hall/CRC Press; 2003.

14. Johnston K, Gray A, Moher M, et al. Reporting the costeffectiveness of interventions with nonsignificant effect differences: Example from the a trial of secondary prevention of heart disease. Int J Technol Assess Health Care. 2003;19:476489.

15. Ketola E, Laatikainen T, Vartianinen E. Evaluating risk for cardiovascular diseases -vain or value? How do different cardiovascular risk scores act in real life. Eur J Public Health. 2010;20:107-112.

16. Lacey EA, Walters SJ. Continuing inequality: Gender and social class influences on self perceived health after a heart attack. J Epidemiol Community Health. 2003;57:622-627. 
17. Manca A, Hawkins N, Sculpher M. Estimating mean QALYs in trial based cost effectiveness analysis: The importance of controlling for baseline utility. Health Econ. 2005;14:487-496.

18. Murphy AW, Cupples ME, Smith S, et al. Secondary prevention of heart disease in general practice: A cluster randomised controlled trial of tailored practice and patient care plans. $B M J$. 2009;339:b4220.

19. Netten A, Curtis J. Unit costs of health and social care. Canterbury: Personal Social Services Research Unit. University of Kent; 2006.

20. National Institute for Clinical Excellence. Guide to the methods of technology appraisal. London: NICE; 2004. www.nice.org.uk/page.aspx?o=201974 (reference 0515).

21. O’Neill C, Normand C, Cupples M, McKnight A. Cost effectiveness of personal health education in primary care for people with angina in the Greater Belfast area of Northern Ireland. J Epidemiol Community Health. 1996;50:538-540.
22. Raftery JP, Yao GL, Murchie P, Campbell NC, Ritchie LD. Cost effectiveness of nurse led secondary prevention clinics for coronary heart disease in primary care: Follow up of a randomised controlled trial. BMJ. 2005;330: 707.

23. Robinson M, Palmer S, Sculpher M, et al. Cost effectiveness of alternative strategies for the initial medical management of non-ST elevation acute coronary syndrome: Systematic review and decision-analytical modelling. Health Technol Assess. 2005;9:iii-iv, ix-xi, 1-158.

24. Turner DA, Paul SK, Stone M, et al. Cost-effectiveness of a disease management programme for secondary prevention of coronary heart disease and heart failure in primary care. Heart. 2008;94:1601-1606.

25. Ware JE, Kosinski M, Keller SD. A 12-item short-form health survey: Construction of scales and preliminary tests of reliability and validity. Med Care. 1996;34:220-233. 